\title{
Bir İl Merkezinde 6-14 Yaş Grubu Çocuklarda ve Ailelerinde Görülen Besin Alerjisi ve Alerjik Hastalıkların Sıklığı
}

\author{
Prevalence of Food Allergy and Allergic Diseases at 6-14 Age Group Children and Their \\ Family in A City Centre
}

\author{
Gönül YARDIMCI ${ }^{1}$, Yakup CANITEZ ${ }^{2}$, Nihat SAPAN ${ }^{2}$, Cennet RAĞBETLI'1 \\ ${ }^{1}$ Ankara Ĕgitim ve Araştırma Hastanesi, Pediatri Kliniği, ANKARA \\ ${ }^{2}$ Uludă̆ Üniversitesi Tıp Fakültesi, Pediatri A.D., Çocuk Alerji Bilim Dalı, BURSA
}

\begin{abstract}
ÖZET
Bu çalışmada bir il merkezinde seçilen 4 okulda okuyan 6-14 yas grubu çocuklarda ve ailelerinde besin alerjisi ve alerjik hastalıkların sıklığının araştırılması amaçlanmıştır.

Tanımlayıcı tipteki bu çalışma Bursa il merkezinde yer alan seçilmiş 4 okulda gerçekleştirilmiştir. Bu okullarda 6-14 yaş grubunda bulunan toplam 4195 çocuktan 3944 çocuğun ebeveyni çalışmaya katılmayı kabul etmiştir (katılım hızı \%94'tür). Çalışmaya katılmayı kabul eden öğrencilerin ebeveynlerine çocuklarında ve aile bireylerinde görülen besin alerjisi ve alerjik hastalıkların sıklığını sorgulayan sorulardan oluşan bir anket formu uygulanmıştır. Çalışma için üniversite etik kurulundan ve milli eğitim müdürlüğünden yazılı izin alınmıştır.

Öğrencilerin $(n=3944)$ yaşam boyu en az bir kez besin alerjisi bulguları varlığı (yaşam boyu veya kümülatif prevalans) \%13.4 (529), doktor tarafindan yaşam boyu en az bir kez besin alerjisi tanısı konması \%6.4 (253) olarak saptanmıştır. Doktor tarafından en az bir kez besin alerjisi tanısı konulan çocukların \%29,6'sının birinci derece aile yakınlarından en az birinde (anne, baba, kardeşler) besin alerjisi öyküsü mevcuttur. Doktor tarafindan yaşam boyu en az bir kez besin alerjisi tanısı konulan çocukların anne veya babasında görülen alerjik hastalıklar sirasiyla besin alerjisi $\% 12,2$, astım $\% 10,7$, alerjik rinit $\% 9,1$, alerjik konjonktivit $\% 5,9$, atopik dermatit $\% 5,1$; kardeşlerindeki alerjik hastalık sıklığı astım \%10,7, alerjik rinit \%9,5, besin alerjisi $\% 9,1$, alerjik konjonktivit \%4,3 olarak saptanmıştır.

Bursa'da ailelerin doldurduğu anketlerle tespit edilen doktor tarafından yaşam boyu en az bir kez besin alerjisi tanısı konulan 6-14 yaş grubu çocuklarda ve aile bireylerinde görülen alerjik hastalığı tespit etmeye yönelik yapılan bu çalışma alerjik hastalık seyrinde aile öyküsünün son derece önemli olduğunu göstermektedir.
\end{abstract}

Anahtar Kelimeler: Alerjik hastalıklar, besin alerjisi, okul çağ popülasyonu, aile bireyleri
ABSTRACT

This study, we aimed to investigate frequency of food allergy and allergic diseases in 6-14 year aged children and their families at selected four schools in a city.

This descriptive study carried out in selected four schools in the central province of Bursa. In these schools, a total of 4195 children in the 6-14 age group and 3944 child's parents have agreed to participate to study (response rate 94\%). We applied a questionnaire about frequency of food allergy and allergic diseases in themselves and their family members to students' parents who agreed to participate to study. Written permission have been taken from university ethics committee and provincial directorate of national education.

Findings of food allergy at least once in their lifetime were determined in $13,4 \%$ of participants $(n=3944)$ and those who had consulted a doctor at least once for food allergy were determined at a rate of $6,4 \%$. In the children diagnosed with food allergy by a doctor at least once, the frequency of food allergy at least one first-degree relatives in the family was $29,6 \%$. In the children diagnosed with food allergy by a doctor at least once, frequency of allergic diseases in their mother or father was food allergy $12,2 \%$, asthma $10,7 \%$, allergic rhinitis $9,1 \%$, allergic conjunctivitis $5,9 \%$, atopic dermatitis $5,1 \%$ respectively and allergic diseases incidence in siblings were found to asthma $10,7 \%$, allergic rhinitis $9,5 \%$, food allergy $9,1 \%$, allergic conjunctivitis $4,3 \%$ respectively.

This questionnaire study which conducted in Bursa, we found that family history is extremely important in progression of allergic diseases.

Keywords: Hypersensivity, food hypersensivity, school-aged population, family members 


\section{GíRiș}

Besin alerjisi (BA) çocukluk çağında sık görülen Alerjik Hastalıklar (AH) arasındadır. Vücuda alınan besin veya besin katkı maddelerine karşı oluşan çeşitli anormal yanıtlar besin reaksiyonları olarak adlandırılmaktadır (1). Gerçek BA, besinlerin içeriğindeki alerjenlere karşı oluşan immünolojik bir reaksiyondur ve sıklığı artmakla birlikte çocukların yaklaşık \%8'ini, erişkinlerin yaklaşık \%5'ini etkilediği bildirilmektedir (2). Türkiye'de yapılan çalışmalarda 69 ve 6-13 yaş grubu çocuklarda BA görülme sıklığının sirasiyla \%5,7-11,2 arasında olduğu tahmin edilmektedir (3-5). Yurtdışında yapılmış çalışmalarda çocuklarda anket yöntemi kullanılarak saptanan BA görülme sıklığı \%1,7-12,8 oranında bildirilmektedir (6$10)$.

Ailede atopik hastalı olması gibi genetik risk faktörleri ile çevresel, kültürel ve beslenme alışkanlıkları gibi etkenler de BA'nın ortaya çıkmasında ve kliniğinde rol oynamaktadır $(11,12)$. Atopik hastalığı olan çocuklarda BA sıklığının daha fazla olduğu bilinmektedir. Orta ve ağır atopik dermatiti olan çocukların yaklaşık \%35'inde IgE aracılı BA mevcuttur ve çoğunda besin alerjenlerinin alımıyla semptomlar alevlenmektedir (13).

'Atopik yürüyüş', çeşitli AH bulgularının doğal seyrini ifade etmektedir. Atopik anne babadan doğan ve atopi genetik yükünü taşıyan bir bebek, yaşamın ilk günlerinden itibaren karşılaştığı alerjenlere cevap verme ve duyarlanma yeteneğine sahiptir. Genellikle ilk karşılaşılan alerjik hastalık atopik dermatit olup bunu BA'ya ait klinik bulgular izlemektedir. Atopik dermatit alerjik sürecin başlangıç noktası olarak kabul edilmektedir. Atopik dermatitli çocukların ailelerinde alerjik hastalık öyküsü sıklıkla bulunmaktadır; çocukların \%80 kadarında serumda IgE düzeyi yüksektir, rinit ve astım gibi solunum yolu alerjik hastalıkları sıklıkla tabloya katılır; besin alerjileri sık olarak saptanmaktadır. Atopik dermatitli olguların pek çoğunda var olan BA hastalık patogenezinde önemli rol oynamaktadır. Yaşamın daha sonraki yıllarında ise solunum alerjenlerine duyarlılık gelişmekte olup astım ve alerjik rinit bulguları tabloya eklenmektedir (14).

$\mathrm{Bu}$ çalışmada bir il merkezinde seçilen 4 okulda okuyan 6-14 yaş grubu çocuklarda ve ailelerinde besin alerjisi ve alerjik hastalıkların sıklığının araştırılması amaçlanmıştır.

\section{GEREÇ VE YÖNTEM}

$\mathrm{Bu}$ çalışma Uludağ Üniversitesi Tıp Fakültesi Çocuk Alerji Bilim Dalı tarafindan, 2010 yılında Bursa il merkezinde rastgele seçilmiş 4 ilköğretim okulunda gerçekleştirilmiştir. Okullardaki 6-14 yaş grubundaki (ana sinıfı, ilköğretim 1-8. sinıflar) toplam 4195 ögrenciye anket formu dağıtılmış, tam ve uygun olarak cevaplayan 3944 anket değerlendirilmeye alınmıştır. Çalışmaya katılım \%94,0 olarak gerçekleşmiştir. Anket formu öğrencilerin, kendilerinde ve aile bireylerinde görülen BA ve AH'nin sıklığını sorgulayan sorulardan oluşmaktadır. İki gün ile beş gün içerisinde okullara tekrar gidilerek formlar geri toplanmıştır. Çalışma için Uludağ Üniversitesi Tıp Fakültesi Etik Kurulu'ndan (08.04.09 tarih ve 2009-6/22 no'lu karar), Bursa İli Milli Eğitim Müdürlüğü’nden ve çalışmanın yapılacağı okullardan yazılı izinler alınmıştır. Ayrıca her bir çocuktan çalışma için aile bilgilendirme ve onam formu alınmıştır. Çalışmada tanımlayıcı veriler sayı (n) ve yüzde (\%) olarak verilmiştir. Gruplar arasındaki farklılığ1 değerlendirmek için Ki-kare Testi kullanılmıştır. İstatistiksel anlamlılık düzeyi olarak $\mathrm{p}<0,05$ kabul edilmiştir.

\section{BULGULAR}

Katılımc1ların \%50,2'si $\quad(n=1978)$ erkek, \%49,8'i $(\mathrm{n}=1966) \quad$ kız çocuklardan oluşmaktadır $\quad(\mathrm{p}>0,05)$. Çocukların yaş ortalaması $10.19 \pm 2.30$ iken, median yaş ise 10,0 olarak bulundu. Çalışmaya katılan olgularda $(n=3944)$ yaşam boyu en az bir kez BA bulguları görülenler \%13,4 olarak bulundu. Doktor tarafindan en az bir kez BA tanısı alma \%6,4 (253) çocukta bildirildiği saptandı. Tüm olgularda doktor 
tanılı AH sırasıyla; astım $(\% 10,9)$, alerjik rinit $(\% 10,2)$, alerjik konjonktivit $(\% 3,9)$, atopik dermatit $(\% 4,3)$, ürtiker $(\% 2,0)$, BA $(\% 6,4)$, ilaç alerjisi $(\% 1,7)$, astım+alerjikrinit+alerjik konjonktivit $\quad(\% 2,4)$, alerjikrinit+alerjik konjonktivit $(\% 2,0)$ olarak saptand1. Yaşam boyu en az bir kez BA bulguları görüldüğü belirtilen çocukların doktor tanılı alerjik hastalıkları sırasıyla; astım $(\% 10,0)$, alerjik rinit $(\% 9,1)$, alerjik konjontivit $(\% 3,6)$, atopik dermatit $(\% 5,7)$, ürtiker $(\% 2,3)$, BA $(\% 47,8)$ ilaç alerjisi $\quad(\% 2,3)$, astım+alerjikrinit+alerjik konjonktivit $(\% 2,0)$, alerjik rinit+alerjik konjonktivit $(\% 2,5)$ olarak saptand1. Bununla birlikte doktor tarafından yaşam boyu en az bir kez BA tanısı konulan çocukların doktor tanılı diğer alerjik hastalıkları sırasıyla; astım $(\% 12,6)$, alerjik rinit $(\% 10,2)$, alerjik konjonktivit $(\% 5,1)$, atopik dermatit $(\% 5,9)$, ürtiker $(\% 3,2)$, ilaç alerjisi $(\% 3,2)$, astım+alerjikrinit+alerjik konjonktivit $(\% 2,8)$, alerjik rinit+alerjik konjonktivit $(\% 3,6)$ olarak saptandı (Tablo 1).

Tablo 1: Olgularda tespit edilen alerjik hastalıkların sıklığg.

\begin{tabular}{|c|c|c|c|c|c|c|}
\hline \multirow[t]{2}{*}{$\begin{array}{l}\text { Doktor Tanılı Alerjik } \\
\text { Hastalıklar }\end{array}$} & \multicolumn{2}{|c|}{$\begin{array}{l}\text { Çalışmaya katılan tüm } \\
\text { çocuklar }(n=3944)\end{array}$} & \multicolumn{2}{|c|}{$\begin{array}{l}\text { Yaşam boyu en az } 1 \mathrm{kez} \\
\text { BA bulguları görüldüğü } \\
\text { belirtilen çocuklar (n: 529) }\end{array}$} & \multicolumn{2}{|c|}{$\begin{array}{l}\text { Doktor tarafindan yaşam } \\
\text { boyu en az } 1 \text { kez BA tanısı } \\
\text { konulan çocuklar (n: 253) }\end{array}$} \\
\hline & $\mathbf{n}$ & $\%$ & $\mathbf{n}$ & $\%$ & $\mathbf{n}$ & $\%$ \\
\hline Astım & 431 & 10,9 & 53 & 10,0 & 32 & 12,6 \\
\hline Alerjik rinit & 401 & 10,2 & 48 & 9,1 & 27 & 10,2 \\
\hline Alerjik konjonktivit & 153 & 3,9 & 19 & 3,6 & 13 & 5,1 \\
\hline Atopik dermatit & 168 & 4,3 & 30 & 5,7 & 15 & 5,9 \\
\hline Ürtiker & 81 & 2,0 & 12 & 2,3 & 8 & 3,2 \\
\hline BA & 253 & 6,4 & 253 & 47,8 & - & - \\
\hline İlaç alerjisi & 68 & 1,7 & 12 & 2,3 & 8 & 3,2 \\
\hline $\begin{array}{l}\text { Astım + Alerjik rinit } \\
\text { +Alerjik konjonktivit }\end{array}$ & 93 & 2,4 & 11 & 2,0 & 7 & 2,8 \\
\hline $\begin{array}{l}\text { Alerjik rinit + } \\
\text { Alerjik konjonktivit }\end{array}$ & 78 & 2,0 & 13 & 2,5 & 9 & 3,6 \\
\hline Alerjik hastalık yok & 2927 & 74,2 & 158 & 29,9 & 150 & 59,3 \\
\hline
\end{tabular}

Yaşam boyu en az bir kez BA bulguları olan çocukların \%28'inin, doktor tarafindan en az bir kez BA tanısı konulan çocukların ise \%29,6'sının birinci derece aile yakınlarından en az birinde (anne, baba, kardeşler) BA öyküsü mevcuttur ve bu farklılık istatistiksel olarak anlamlı değildir (Tablo 2).

Doktor tarafından yaşam boyu en az bir kez BA tanısı konulan çocukların anne veya babasındaki alerjik hastalıklar sırasıyla; astım $(\% 10,7)$, alerjik rinit $(\% 9,1)$, alerjik konjonktivit $(\% 5,9)$, atopik dermatit $(\% 5,1)$, ürtiker $(\% 4,3)$, BA $(\% 12,2)$, ilaç alerjisi $(\% 4,7)$, astım+alerjikrinit+alerjik konjonktivit (\%4,0), alerjikrinit+alerjik konjonktivit $(\% 3,2)$ olarak saptand 1 (Tablo 3). 
Tablo 2: Çocukların birinci derece aile yakınlarından en az birinde (anne, baba, kardeşler) BA öyküsü bulunma durumu.

\begin{tabular}{|c|c|c|c|c|c|c|c|}
\hline \multirow[t]{2}{*}{ Besin Alerjisi } & \multicolumn{2}{|c|}{$\begin{array}{l}\text { Yaşam boyu en az } 1 \text { kez BA } \\
\text { bulguları görüldüğü } \\
\text { belirtilen çocuklar (n: 529) }\end{array}$} & \multicolumn{2}{|c|}{$\begin{array}{l}\text { Doktor tarafindan yaşam } \\
\text { boyu en az } 1 \text { kez BA tanısı } \\
\text { konulan çocuklar (n: } 253 \text { ) }\end{array}$} & \multicolumn{3}{|c|}{ Toplam } \\
\hline & $\mathbf{n}$ & $\%$ & $\mathbf{n}$ & $\%$ & n & $\%$ & $\mathbf{p}$ \\
\hline Var & 148 & 28,0 & 75 & 29,6 & 223 & 100,0 & 0,31 \\
\hline Yok & 381 & 72,0 & 178 & 70,4 & 559 & 100,0 & \\
\hline Toplam & 529 & 67,6 & 253 & 32,4 & 782 & 100,0 & \\
\hline
\end{tabular}

Tablo 3: Doktor tarafından yaşam boyu en az bir kez BA tanısı konulan çocukların (n: 253) anne ve/veya babasındaki alerjik hastalıkların sıklığı.

\begin{tabular}{|c|c|c|}
\hline $\begin{array}{l}\text { Anne ve/veya } \\
\text { Babadaki Alerjik } \\
\text { Hastalıklar }\end{array}$ & $\begin{array}{l}\text { Doktor tarafindan } \\
\text { boyu en az } 1 \text { kez B } \\
\text { konulan çocuklar }\end{array}$ & $\begin{array}{l}\text { yaşam } \\
\text { A tanısı } \\
(n: 253)\end{array}$ \\
\hline & $\mathbf{n}$ & $\%$ \\
\hline $\mathbf{B A}$ & 31 & 12,2 \\
\hline Astım & 27 & 10,7 \\
\hline Alerjik rinit & 20 & 9,1 \\
\hline Alerjik konjonktivit & 15 & 5,9 \\
\hline Atopik dermatit & 13 & 5,1 \\
\hline Ürtiker & 11 & 4,3 \\
\hline İlaç alerjisi & 12 & 4,7 \\
\hline Astım+Alerjik rinit+ & 10 & 4,0 \\
\hline \multicolumn{3}{|l|}{ Alerjik konjonktivit } \\
\hline $\begin{array}{l}\text { Alerjik rinit+Alerjik } \\
\text { konjonktivit }\end{array}$ & 8 & 3,2 \\
\hline Alerjik hastalık yok & 155 & 61,3 \\
\hline
\end{tabular}

*Yüzdeler BA tanısı konulan 253 çocuk üzerinden hesaplanmıştır.

Doktor tarafından yaşam boyu en az bir kez BA tanısı konulan çocukların kardeşlerindeki alerjik hastalıklar sırasıyla; astım $(\% 10,7)$, alerjik rinit $(\% 9,5)$, alerjik konjonktivit $(\% 4,3)$, atopik dermatit $(\% 2,8)$, ürtiker $(\% 4,0)$, BA $(\% 9,1)$, ilaç alerjisi $(\% 1,6)$, astım+alerjik rinit+alerjik konjonktivit $(\% 4,0)$, alerjik rinit+alerjik konjonktivit $(\% 2,8)$ olarak saptandı (Tablo 4).

Tablo 4: Doktor tarafından yaşam boyu en az bir kez BA tanısı konulan çocukların (n: 253) kardeşlerindeki alerjik hastalıkların sıklığı.

\begin{tabular}{lcc}
\hline Kardeşlerdeki Alerjik & n & \%* \\
Hastalıklar & & \\
\hline Astım & 27 & 10,7 \\
Alerjik rinit & 24 & 9,5 \\
BA & 23 & 9,1 \\
Alerjik konjonktivit & 11 & 4,3 \\
Ürtiker & 10 & 4,0 \\
Astım+Alerjik rinit+Alerjik & 10 & 4,0 \\
konjonktivit & & \\
Alerjik rinit+Alerjik & 7 & 2,8 \\
konjonktivit & & \\
Atopik dermatit & 7 & 2,8 \\
İlaç alerjisi & 4 & 1,6 \\
Alerjik hastalık yok & 155 & 61,3 \\
\hline
\end{tabular}

*Yüzdeler BA tanısı konulan 253 çocuk üzerinden hesaplanmıştır. 


\section{TARTIŞMA}

Bursa il merkezinde 6-14 yaş grubu çocuklarda ve ebeveynlerinde BA ve AH sıklığını araştırmaya yönelik bu çalışmada doktor tarafından BA tanısı konulan bu yaş grubu çocuklarda en sık gözlenen alerjik hastalıklar sırasıyla astım \%12,6, alerjik rinit $\% 10,2$ ve atopik dermatit $\% 5,9$ olarak saptanmıştır.

Astım için majör risk faktörleri; yaşamın ilk yılı içinde başlayan besin duyarlılı̆̆ı ve yaşamın ilk 2 yılı içinde başlayan inhalan alerjen duyarlılığı olarak bulunmuştur (15). İnek sütü ve yumurta gibi besin alerjilerinin erken dönemde başlayan atopik dermatit ile birlikteliği dikkat çekici olup, çeşitli çalışmalarda BA saptanan atopik dermatitli olgularda, özellikle küçük çocuklarda hastalık bulguları daha şiddetli seyretmekte ve bunun da sonradan astım ve diğer solunum yolu alerjilerinin gelişmesinde risk oluşturduğu bildirilmektedir $(16,17)$. Toplum tabanlı çalışmalarda BA'nın astım ve bronşial hiperreaktivite ile birlikteliği dikkat çekmektedir (18). NHANES (National Health and Nutrition Examination Survey)'in 2005-2006 yılları arasında BA'nın sıklığını, BA için demografik risk faktörlerini ve BA'nın astımla ilişkisini inceledikleri çalışmada BA olanlarda astım görülme sıklığının 3,8 kat ve ağır astım nedeniyle acile başvuruların 6,9 kat daha fazla olduğu saptanmıştır. Alerjik rinit ve egzamanın da BA olanlarda daha sık gözlendiği saptanmıştır (19). BA ile astımın ilişkili olduğunu gösteren başka çalışmalar da vardır $(20,21)$. Schäfer ve ark.'nın (22) çalışmasında da BA olan kişilerde ürtiker, astım, atopik dermatit ve alerjik rinitin daha sık gözlendiği, en kuvvetli ilişkinin ise alerjik rinit ile olduğu ve BA olanların \%73,1'inde alerjik rinit saptandığı rapor edilmiştir. Hofer ve ark.'nın (23) çalışmasında BA olanların \%65'inde diğer alerjik hastalıkların gözlendiği belirtilmiştir. Güney Afrikalı atopik dermatitli çocuklarda anket, deri prik testi, ISAC (Immuno Solid Phase Allergen Chip) testi ve besin yükleme testleri kullanılarak BA'nın araştırıldığı bir çalışmada; 6 ay 10 yaş arası ortanca yaşı 42 ay olan 100 atopik dermatit hastasında besin aşırı duyarlılı̆̆
$\% 66$, BA $\% 40$ olarak belirlenmiş, en alerjik besinler yumurta (\%25) ve yer fistığı (\%24) olarak bulunmuştur (24). Kore'de atopik dermatitli erişsin hastalarda besin aşırı duyarlılığının araştırıldığı bir çalışmada, 126 hastanın 33'ünde $(\% 26,2)$ öncesinde besin aşırı duyarlılığının olduğu tespit edilmiştir (25). Seul, Kore'de yapılan bir başka çalışmada ise ISAAC anketi kullanılarak toplam 8750 okul öncesi (0-6 yaş) ve ilkokul (7-12 yaş) çağı çocukta atopik dermatit risk faktörleri araştırılmış ve her iki dönemde de ailesel atopik hastalık öyküsünün, alerjik konjonktivit ve BA tanılarının atopik dermatit ile pozitif korele olduğu saptanmıştır (26).

Çalışmamızda doktor tarafından en az bir kez BA tanısı konulan 253 çocuğun $75^{\prime}$ inde $(\% 29,6)$ birinci derece aile yakınlarından en az birinde (anne, baba, kardeşler) BA öyküsü mevcuttur. Rance ve ark.'nın çalışmasında anket değerlendirmelerinden BA olan çocukların \%81,3'ünde ailede atopik hastalık öyküsü saptanmıştır; ailede BA öyküsü ise BA olan çocukların \%12,8'inde saptanmıştır. Gaspar-Marques ve ark.'nın (27) Portekiz'de ortanca yaşları 3,5 olan 1217 infant ve okul öncesi çocuğu kapsayan ailelerin doldurduğu ankete dayalı çalışmasında ebeveynlerinde BA öyküsü olanlarda ve öncesinde atopik dermatit öyküsü olanlarda BA'nın daha sık görüldüğünü saptamışlardır.

Çalışmamızda doktor tarafindan yaşam boyu en az bir kez BA tanısı konulan çocukların anne veya babasında en sık BA $(\% 12,2)$ sonra sirasiyla astım $(\% 10,7)$ ve alerjik rinit $(\% 9,1)$ saptanmış; kardeşlerinde ise en sık astım $(\% 10,7)$ sonra sirasıyla alerjik rinit $(\% 9,5)$ ve BA $(\% 9,1)$ saptanmıştır.

Alerjik hastalıklarda genetik faktörler etiyolojide ilk sıralarda sorumlu tutulmaktadır. Anne, baba veya kardeşinde alerji öyküsü olan kişilerde $\mathrm{AH}$ riski artmaktadır. BA saptanan olguların aile hikâyelerinde atopik dermatit, astım, rinokonjonktivit birliktelikleri s1k görülmektedir (28-31). Osterballe ve ark.'nın çalışmasında, 3 yaş grubunda oral yükleme testleri ile 
desteklenen BA sıklığı \%2,3, kardeşlerinde \%1 ve ebeveynlerinde \%3,2 olarak saptanmıştır (32). Gelincik ve ark.'nın İstanbul'da erişkinler üzerinde yaptıkları toplum tabanlı bir çalışmada, BA sıklığını etkileyen en önemli faktörlerin ailesel atopi öyküsü ve dermatit, ürtiker gibi atopik hastalıkların birlikteliği olduğu görülmüştür. Ailesel atopi öyküsünün BA sılı̆̆ı̆ı 4,3 kat ve dermatit, ürtiker gibi ilişkili atopik hastalıların BA sıklığını 3,9 kat artırdığı saptanmıştır (33). Sarafino, BA'yı da içine alan atopik hastalıklar için ebeveyn-çocuk ilişkisini araştırmış ve ebeveynlerinde atopik hastalık öyküsü olan çocuklarda astım, egzama, alerjik rinit ve BA'nın daha sık geliştiğini saptamıştır (34).

Koplin ve arkadaşları oral gıda yükleme testi ile destekli BA tanılı 534 bir yaş infantta ailesel alerji öyküsünün çocukta BA için risk oluşturup oluşturmadığını araştırmışlar ve aile bireylerinde hiç AH öyküsü olmayanlara kryasla aile bireylerinden birinde AH öyküsü olanlarda 1,4 kat; aile bireylerinden iki veya daha fazlasında $\mathrm{AH}$ öyküsü olanlarda ise 1,8 kat fazla BA'nın görüldüğünü saptamışlardır (35).

$\mathrm{Bu}$ çalışmada doktor tarafından BA tanısı konulan çocukların aile bireylerinde BA'nın sık gözlendiği ve BA tanısı konulan bu çocuklarda ve anne, baba ve kardeşlerinde diğer alerjik hastalıkların da daha sık olarak görüldüğü saptanmıştır. $\mathrm{Bu}$ durum göz önüne alınarak ailesinde ve kendisinde alerjik hastalık öyküsü olan çocukların, besin alerjisine daha yatkın olduğu söylenebilir.

\section{KAYNAKLAR}

1. Boyce JA, Assa'ad A, Burks AW, Jones SM, Sampson HA, Wood RA et al. Guidelines for the Diagnosis and Management of Food Allergy in the United States: Report of the NIAID-Sponsored Expert Panel. J Allergy Clin Immunol. 2010; 126 (60): 1-58.
2. Sicherer SH and Sampson HA. Food allergy: Epidemiology, pathogenesis, diagnosis, and treatment. J Allergy Clin Immunol. 2014;133 (2):291-307.

3. Yıldırım M, Ergür AT, Saraçlar Y, Tuncer A. Sivas İl Merkezinde Çocuklarda Allerjik Hastalıkların Prevalansı. Çocuk Sağlığı ve Hastalıkları Dergisi. 2002; 45 (3): 226-32.

4. Saraçlar Y, Yiğit Ş, Adalıŏlu G, Tuncer A, Tunçbilek E. Prevalence of allergic disease and influencing factors in primary-school children in the Ankara region of Turkey. J Asthma. 1997; 34 (1): 23-30.

5. Orhan F, Karakas T, Cakir M, Aksoy A, Baki A, Gedik Y. Prevalence of immunoglobulin Emediated food allergy in 6-9-year-old urban schoolchildren in the eastern Black Sea region of Turkey. Clin Exp Allergy. 2009; 39 (7): 1027-35.

6. Dubakiene R, Surkiene G, Stukas R, Vilesko JP, Kavaliunas A. Food allergies among 5th-9th grade schoolcildren in Vilnius (Lithuania). Ekologia. 2008; 54 (1): 1-4.

7. Steinke M, Fiocchi A, Kirchlechner V, BallmerWeber B, Brockow K, Hischenhuber C, et al. Perceived food allergy in children in 10 European nations. Int Arch Allergy Immunol. 2007; 143 (4): 290-5.

8. Eggesbo M, Halvorsen R, Tambs K, Botten G. Prevalance of parentally percived adverse reactions to food in young children. Pediatr Allergy Immunuol. 1999; 10 (2): 122-32.

9. Rona RJ, Chinn S. Parent's perception of food intolerance in primary school children. $\mathrm{Br}$ Med $\mathrm{J}$. 1987; 294 (6576): 863-6.

10. Rance F, Grandmottet X, Grandjean H. Prevalance and main characteristic of schoolchildren diagnosed with food allergies in France. Clin Exp Allergy. 2005; 35(2): 167-72. 
11. Wood RA. The natural history of food allergy. Pediatrics. 2003; 111(6 Pt 3): 1631-7.

12. Sicherer SH, Munoz-Furlong A, Sampson HA. Prevalence of peanut and tree nut allergy in the United States determined by means of a random digit dial telephone survey: a 5-year follow-up study. J Allergy Clin Immunol. 2003; 112 (6): 1203-7.

13. Eigenmann PA, Sicherer SH, Borkowski TA, Cohen BA, Sampson HA. Prevalence of IgEmediated food allergy among children with atopic dermatitis. Pediatrics. 1998; 101 (3): E8.

14. Spergel JM, Paller AS. Atopic dermatitis and the atopic march. J Allergy Clin Immunol. 2003; 112 (6): 118-27.

15. Rhodes HL, Sporik R, Thomas P, Holgate St, Cogswell JJ. Early life risk factors for adult asthma: a birth cohort study of subjects at risk. J Allergy Clin Immunol. 2001; 108 (5): 720-5.

16. Burks AW, James JM, Hiegel A, Wilson G, Wheeler JG, Jones SM, et al. Atopic dermatitis and food hypersensitivity reactions. J Pediatr. 1998; 132 (1): 132-6.

17. Kulig M, Bergmann R, Klettke U, Wahn V, Tacke U, Wahn U. Natural course of sensitization to food and inhalant allergens during the first 6 years of life. J Allergy Clin Immunol. 1999; 103 (6): 11739.

18. Björnsson E, Janson C, Plaschke P, Norrman E, Sjöberg O. Prevalence of sensitization to food allergens in adult Swedes. Ann Allergy Asthma Immunol. 1996; 77 (4): 327-32.

19. Liu AH, Jaramillo R, Sicherer SH, Wood RA, Bock SA, Burks AW, Massing M, Cohn RD, Zeldin DC. National prevalence and risk factors for food allergy and relationship to asthma: Results from the National Health and Nutrition Examination Survey 2005-2006. J Allergy Clin Immunol. 2010; 126 (4): 798-806.e13
20. Sicherer SH, Munoz-Furlong A, Sampson HA. Prevalance of seafood allergy in the United States determined by a random telephone survey. J Allergy Clin Immunol. 2004; 114 (1): 159-65.

21. Branum AM, Lukacs SL. Food allergy among children in the United States. Pediatrics. 2009; 124 (6): 1549-55.

22. Schäfer T, Böhler E, Ruhdorfer S, Weigl L, Wessner D, Heinrich J, Filipiak B, Wichmann HE, Ring J. Epidemiology of food allergy/food intolerance in adults: associations with other manifestations of atopy. Allergy. 2001; 56 (12): 1172-9.

23. Hofer T, Wüthrich B. Food allergy. II. Prevalence of organ manifestations of allergy-inducing food. A study on the basis on 173 cases, 1978-1982. Schweiz Med Wochenschr. 1985; 115 (41): 143742.

24. Gray CL, Levin ME, Zar HJ, Potter PC, Khumalo NP, Volkwyn L, Fenemore B, du Toit G. Food allergy in south african children with atopic dermatitis. Pediatr Allergy Immunol. 2014; 25(6): 572-9. doi: 10.1111/pai.12270.

25. Yang YS, Byun YS, Kim JH, Kim HO, Park CW. Food hypersensitivity in adult patients with atopic dermatitis in Korea. Clin Exp Dermatol. 2015; 40(1): 6-10. doi: 10.1111/ced.12433. Epub 2014 Sep 15 .

26. Baek JO, Hong S, Son DK, Lee JR, Roh JY, Kwon HJ. Analysis of the prevalence of and risk factors for atopic dermatitis using an ISAAC questionnaire in 8,750 Korean children. Int Arch Allergy Immunol. 2013; 162(1): 79-85. doi: 10.1159/000351403.

27. Gaspar-Marques J, Carreiro-Martins P, Papoila AL, Caires I, Pedro C, Araújo-Martins J, Virella D, Rosado-Pinto J, Leiria-Pinto P, Neuparth N. Food Allergy and Anaphylaxis in Infants and Preschool- 
Age Children. Clin Pediatr (Phila). 2014; 53(7): 652-57.

28. Sampson HA, Burks AW. Adverse Reactions to Foods. Middleton's Allergy: Principles and Practice: 7th edition. China: Elsevier; 2009: 113967.

29. Sampson HA. Update on food allergy. J Allergy Clin Immunol. 2004; 113(5): 805-19.

30. Bock SA, Munoz-Furlong A, Sampson HA. Further fatalities caused by anaphylactic reactions to food, 2001-2006. J Allergy Clin Immunol. 2007; 119(4): 1016-8. Epub 2007 Feb 15.

31. Asher MI, Keil U, Anderson HR, Beasley R, Crane J, Martinez F, Mitchell EA, Pearce N, Sibbald $\mathrm{B}$, Stewart AW. International study of asthma and allergies in childhood (ISAAC): rationale and methods. Eur Resp J. 1995; 8 (3): 483-91.

32. Osterballe M, Hansen TK, Mortz CG, Host A, Bindslev-Jensen C. The prevalance of food hypersensitivity in an unselected population of children and adults. Pediatr Allergy Immunol. 2005; 16(7): 567-73.

33. Gelincik A, Büyüköztürk S, Gül H, Işik E, Işsever H, Ozşeker F, Colakoğlu B, Dal M, Ayvaz O, Güngör G, Akkor A. Confirmed prevalence of food allergy and non-allergic food hypersensitivity in a Mediterranean population. Clin Exp Allergy. 2008; 38(8): 1333-41. doi: 10.1111/j.13652222.2008.03019.x. Epub 2008 Jun 4.

34. Sarafino EP. Connections among parent and child atopic illness. Pediatr Allergy Immunol 2000; 11(2): 80-6.

35. Koplin JJ, Allen KJ, Gurrin LC, Peters RL, Lowe AJ, Tang ML, Dharmage SC; HealthNuts Study Team. The Impact of Family History of Allergy on Risk of Food Allergy: A Population-Based Study of Infants. Int J Environ Res Public Health. 2013; 10(11):5364-77. doi: 10.3390/ijerph10115364. 